\title{
Patient-specific iPSC-derived photoreceptor precursor cells as a means to investigate retinitis pigmentosa
}

\author{
Budd A Tucker ${ }^{1}$, Robert F Mullins ${ }^{1}$, Luan M Streb ${ }^{1}$, Kristin Anfinson ${ }^{1}$, \\ Mari E Eyestone', Emily Kaalberg', Megan J Riker', Arlene V Drack', \\ Terry A Braun ${ }^{1,2}$, Edwin M Stone ${ }^{1,3 *}$ \\ ${ }^{1}$ Department of Ophthalmology and Visual Sciences, University of lowa Carver \\ College of Medicine, lowa City, United States; ${ }^{2}$ Department of Biomedical \\ Engineering, University of lowa Carver College of Medicine, lowa City, United States; \\ ${ }^{3}$ Howard Hughes Medical Institute, University of lowa, lowa City, United States
}

*For correspondence: edwinstone@uiowa.edu

Competing interests: The authors declare that no competing interests exist.

Funding: See page 15

Received: 10 April 2013

Accepted: 24 July 2013

Published: 27 August 2013

Reviewing editor: Jeremy Nathans, Johns Hopkins University School of Medicine, United States

(c) Copyright Tucker et al. This article is distributed under the terms of the Creative Commons Attribution License, which permits unrestricted use and redistribution provided that the original author and source are credited.

\begin{abstract}
Next-generation and Sanger sequencing were combined to identify disease-causing USH2A mutations in an adult patient with autosomal recessive RP. Induced pluripotent stem cells (iPSCs), generated from the patient's keratinocytes, were differentiated into multi-layer eyecup-like structures with features of human retinal precursor cells. The inner layer of the eyecups contained photoreceptor precursor cells that expressed photoreceptor markers and exhibited axonemes and basal bodies characteristic of outer segments. Analysis of the USH2A transcripts of these cells revealed that one of the patient's mutations causes exonification of intron 40 , a translation frameshift and a premature stop codon. Western blotting revealed upregulation of GRP78 and GRP94, suggesting that the patient's other USH2A variant (Arg4192His) causes disease through protein misfolding and ER stress. Transplantation into 4-day-old immunodeficient $\mathrm{Crb}^{-1-}$ mice resulted in the formation of morphologically and immunohistochemically recognizable photoreceptor cells, suggesting that the mutations in this patient act via post-developmental photoreceptor degeneration.

DOI: 10.7554/eLife.00824.001
\end{abstract}

\section{Introduction}

Usher syndrome is a genetically heterogeneous autosomal recessive disorder characterized by early onset sensorineural hearing loss and later onset retinitis pigmentosa (RP). Mutations in the USH2A gene are the most common cause of Usher syndrome type I (Aller et al., 2006; Baux et al., 2007; DePristo et al., 2011) and are also a common cause of non-syndromic RP (McGee et al., 2010; Vaché et al., 2012). The combination of hearing loss and retinitis pigmentosa in Usher syndrome creates an unusual opportunity for the development of effective gene replacement therapy. Unlike many other forms of retinitis pigmentosa in which a large fraction of the photoreceptors have already been lost by the time a diagnosis is made, newborn hearing tests coupled with increasingly sensitive molecular testing have the potential to identify patients affected with Usher syndrome early enough that the majority of their photoreceptors are still amenable to gene replacement therapy.

The obstacles to such treatment include the large size of the USH2A gene, which precludes the use of the types of viral vectors currently employed for retinal gene therapy. Large genes also frequently harbor a number of rare variants of uncertain pathogenicity in the population, and these can make it difficult to establish a molecular diagnosis with sufficient certainty to undertake a therapy as invasive as subretinal injection of therapeutic viruses. Another obstacle to treatment is the relative paucity of information about the normal function of the protein encoded by USH2A (usherin) and the degree to which it can be overexpressed in human cells without causing harm. 
eLife digest Retinitis pigmentosa is an inherited disorder in which the gradual degeneration of light-sensitive cells in the outer retina, known as photoreceptors, causes a progressive loss of sight. Retinitis pigmentosa can also occur as part of a wider syndrome: patients with Usher syndrome, for example, suffer from early-onset deafness and then develop retinitis pigmentosa later in life. Usher syndrome is caused by mutations in any of more than ten genes, but the most commonly affected is USH2A, which encodes a protein called usherin. Mutations in USH2A can also cause retinitis pigmentosa on its own.

Clinical trials are underway to determine whether it is possible to treat various forms of inherited retinal degeneration using gene therapy. This involves inserting a functional copy of the gene associated with the disease into an inactivated virus, which is then injected into the eye. The virus carries the target gene to the light-sensitive photoreceptor cells where it can replace the faulty gene. This could be particularly useful for conditions such as Usher syndrome, in which the earlyonset deafness makes it possible to diagnose retinitis pigmentosa before substantial numbers of photoreceptor cells have been lost.

For gene therapy to become a widely used strategy for the treatment of retinal degenerative disease, identification and functional interrogation of the disease-causing gene/mutations will be critical. This is especially true for large highly polymorphic genes such as USH2A that often have mutations that are difficult to identify by standard sequencing techniques. Likewise, viruses that can carry large amounts of genetic material, or endogenous genome editing approaches, will need to be developed and validated in an efficient patient-specific model system.

Tucker et al. might have found a way to address these problems. In their study, they used skin cells from a retinitis pigmentosa patient with mutations in USH2A to produce induced pluripotent stem cells. These are cells that can be made to develop into a wide variety of mature cell types, depending on the exact conditions in which they are cultured. Tucker et al. used these stem cells to generate photoreceptor precursor cells, which they transplanted into the retinas of immunesuppressed mice. The cells developed into normal-looking photoreceptor cells that expressed photoreceptor-specific proteins.

These results have several implications. First, they support the idea that stem cell-derived retinal photoreceptor cells, generated from patients with unknown mutations, can be used to identify disease-causing genes and to interrogate disease pathophysiology. This will allow for a more rapid development of gene therapy strategies. Second, they demonstrate that USH2A mutations cause retinitis pigmentosa by affecting photoreceptors later in life rather than by altering their development. This suggests that it should, via early intervention, be possible to treat retinitis pigmentosa in adult patients with this form of the disease. Third, the technique could be used to generate animal models in which to study the effects of specific disease-causing mutations on cellular development and function. Finally, this study suggests that skin cells from adults with retinitis pigmentosa could be used to generate immunologically matched photoreceptor cells that can be transplanted back into the same patients to restore their sight. Many questions remain to be answered before this technique can be moved into clinical trials but, in the meantime, it will provide a new tool for research into this major cause of blindness.

DOI: 10.7554/eLife.00824.002

The advent of induced pluripotent stem cells (iPSCs) (Takahashi and Yamanaka, 2006) and the ability to make tissue-specific progenitors from these cells have created a path for overcoming many of these obstacles. It is now possible to investigate the function and dysfunction of a disease-associated gene in tissues such as retina that are inaccessible to molecular analysis in living patients (Tucker et al., 2011; Jin et al., 2012; Singh et al., 2013). For instance, in a recent study, we sequenced the exome of an individual with RP who had no family history of eye disease and only one living sibling and identified a likely disease-causing homozygous mutation in a gene (MAK) that had not been previously reported to be associated with disease (Tucker et al., 2011). We validated this finding in a large cohort of RP patients and then used fibroblast-derived iPSCs from the proband to investigate the mechanism through which the mutation causes disease (Tucker et al., 2011).

The generation of iPSCs from older individuals is more difficult and less efficient than the generation of iPSCs from young individuals (Mahmoudi and Brunet, 2012). To help overcome this limitation, a 
variety of different reprogramming factors, reprogramming enhancers, and cell types have been evaluated (Liao et al., 2008; Judson et al., 2009; Mali et al., 2010; Cheng et al., 2011; Niibe et al., 2011; Szablowska-Gadomska et al., 2011; Zhang et al., 2011; Li and Rana, 2012; Lin et al., 2012; Liu et al., 2012; Mahmoudi and Brunet, 2012; Okita et al., 2013; Zhang and Wu, 2013). Of the accessible cell types used for iPSC generation, the reprogramming of keratinocytes has been shown to be as much as 100-fold more efficient and at least twofold faster than the reprogramming of dermal fibroblasts (Aasen et al., 2008). In addition, it has recently been shown that keratinocyte-derived iPSCs are more similar to embryonic stem cells than those generated from fibroblasts (Barrero et al., 2012).

The ability to create otherwise inaccessible tissues like retina from patient-derived iPSCs provides a valuable tool for the study of disease pathophysiology and the development of treatment. However, the utility of this approach is limited by one's ability to generate relatively pure cultures of the cell type of interest. As clearly demonstrated in a variety of recent publications, early passage iPSCs tend to retain an epigenetic profile that is characteristic of their somatic tissue of origin (Marchetto et al., 2009; Kim et al., 2011). An excellent example of how epigenetic memory can influence retinal differentiation is the recent study by Clegg et al. (Hu et al., 2010), who showed that iPSCs generated from retinal pigmented epithelium (RPE) would preferentially re-differentiate into mature RPE. Although viable retinal tissue suitable for iPSC generation would be difficult to obtain for the purpose of patientspecific disease modeling and therapy, accessible somatic cells from the same germ lineage as the neural retina are readily available in the form of keratinocytes.

In addition to being a useful tool for investigation of disease pathophysiology, iPSC technology provides a means for future autologous photoreceptor transplantation for the treatment of retinal degeneration. Work from Ali et al. clearly demonstrates that the post-mitotic photoreceptor precursor cell is the optimal cell type for efficient rod photoreceptor cell replacement (Lakowski et al., 2011; Pearson et al., 2012). A variety of different protocols, utilizing both two- and three-dimensional culture systems, have succeeded in deriving photoreceptor precursor cells from less differentiated precursors (Osakada et al., 2008; Hirami et al., 2009; Meyer et al., 2009; Osakada et al., 2009; Lamba et al., 2010; Meyer et al., 2011; Tucker et al., 2011; Nakano et al., 2012; Phillips et al., 2012; Sasai et al., 2012; Homma et al., 2013; Mekala et al., 2013; Tucker et al., 2013). Although cultured three-dimensional eyecups will undoubtedly have many applications in developmental biology (Nakano et al., 2012; Sasai et al., 2012), two-dimensional systems have the advantage of easier identification and isolation of specific cell types for post-differentiation subculture. We and others have shown that following transplantation, iPSC-derived photoreceptor precursor cells give rise to rod and cone photoreceptor precursors, which integrate within the dystrophic retina, form synapses with host bipolar cells, and induce a partial restoration of electrophysiological and anatomical correlates of retinal function (Lamba et al., 2010; Tucker et al., 2011; Homma et al., 2013). Isolation of specific cell types from two-dimensional iPSC-derived eyecups followed by transplantation into animal eyes provides a means for exploring human retinal pathophysiology in unprecedented detail, as well as a means for efficiently evaluating gene-based and cell-based therapies.

In this study, we combined Sanger sequencing, next-generation sequencing, and iPSC technologies to identify the disease-causing USH2A mutations in a 62-year-old patient with retinitis pigmentosa and to demonstrate that the mutations we identified are present in the patient's retinal transcripts. In addition, we were able to show that the patient's iPSC-derived rod photoreceptor precursor cells could integrate within the immune suppressed developing mouse retina and give rise to morphologically and immunohistochemically recognizable photoreceptor cells. These findings suggest that the USH2A mutations in this patient act via post-developmental photoreceptor degeneration rather than an early developmental abnormality.

\section{Results}

Genomic DNA from a patient affected with autosomal recessive retinitis pigmentosa (RP) was fragmented and hybridized to an Agilent exome capture reagent (v2), and the eluted fragments were sequenced on an Illumina sequencing instrument. This experiment yielded 71 million uniquely mapped paired-end sequences, each end $50 \mathrm{bp}$ in length. These sequences were aligned to the reference human genomic sequence (hg19) using BWA (Li and Durbin, 2009) and BFAST (Homer et al., 2009). Departures from the reference were identified with GATK (DePristo et al., 2011). More than 20,000 sequence variations were detected (Supplementary file 1B). These variants were prioritized using the following criteria: GATK variation quality score greater than 50 , presence in coding sequence or within 5 bp of a splice 
junction, annotated frequency of less than $2 \%$ in all available population databases, presence in two or fewer exome sequences from other individuals analyzed by our laboratory, predicted to alter protein structure, and lack of complete genotype sharing with the proband's unaffected sibling (as determined by genomewide SNP genotyping) (Supplementary file 1B). After applying these filters to the data, more than 400 plausible disease-causing sequence variations, in more than 300 genes, remained for further consideration. There were no instances of two plausible disease-causing variants in a gene previously associated with RP, but two human retinal degeneration genes ( $A B C A 4$ and USH2A) each harbored a single plausible disease-causing variant (Thr1428Met ACG >ATG and Arg4192His CGC>CAC, respectively). Sanger sequencing of the entire coding sequence of both of these genes confirmed the presence of the heterozygous variants identified by exome sequencing but failed to detect a second disease-causing variation in either gene. We then began evaluating genes that had not been previously associated with human retinal disease that contained two protein-altering variants in the proband. As we were screening additional RP patients and controls for these variants, two things occurred that re-directed our attention to USH2A. First, we discovered a second RP patient with the Arg4192His variant in USH2A, and this individual had a second well-established disease-causing mutation on the opposite USH2A allele. More importantly, Vaché et al. (2012) published their discovery of a diseasecausing variant in intron 40 of USH2A. Sanger sequencing of intron 40 in our patient revealed this intronic variant to be present in trans to his Arg4192His mutation.

To validate the pathogenicity of these mutations in retinal tissue, and to begin developing a cell replacement therapy, we developed an iPSC line from our patient using a primary culture of keratinocytes as the starting material. Like retina, keratinocytes are of ectodermal origin and are significantly easier to reprogram than fibroblasts (Aasen et al., 2008). This is especially important when trying to generate iPSCs from older individuals.

The proband's keratinocytes (Figure 1A) were expanded for three passages prior to being reprogrammed into iPSCs (Tucker et al., 2013). For iPSC generation, passage-4 cells were plated at a density of 30,000 cells $/ \mathrm{cm}^{2}$ and transduced with the transcription factors OCT4, SOX2, KLF4, and C-MYC. Approximately, 7 days post-transduction, cells were passaged at a density of 10,000 cells $/ \mathrm{cm}^{2}$ onto fresh Synthemax cell culture plates and fed every other day with fresh iPSC induction media. 2-3 weeks following the initial passage, small, morphologically distinct cell clusters were present (Figure 1B). 2-3 weeks later, cell colonies large enough for mechanical isolation were dissected from the surrounding differentiated keratinocyte layer. Each isolated colony was dissociated into 150-200 $\mu \mathrm{m}$ square cell clusters and cultured in individual wells of a 24-well Synthemax cell culture plate. Each well was maintained as a separate clonally expanded line for four passages prior to analysis. At passage 4, cultures contained well-defined densely packed colonies consisting of cells with a high nucleus to cytoplasm ratio (Figure 1C, RP-iPSC). To test pluripotency, rt-PCR and teratoma assays were performed. rt-PCR analysis confirmed expression of the pluripotency markers DNMT, LIN28, OCT4, KLF4, SOX2, Nanog, and C-MYC (Figure 1D).

Histologic analysis of teratomas revealed tissues specific to each of the three embryonic germ layers (Figure 1E,F). Similarly, immunohistochemical staining revealed GFAP positive neural tissue (Figure 1G) and aSMA positive vascular structures (Figure $1 \mathrm{H}$ ).

To derive retinal neurons from these iPSCs for pathophysiologic studies and the development of patient-specific therapy, a slightly modified version of our previously published stepwise differentiation protocol was used (Figure 2A) (Tucker et al., 2011, 2011, 2013). This protocol is designed to maximize the percentage of retinal cells produced by taking into account: (1) the role of bone morphogenic protein (BMP) and Wnt signaling pathway inhibition in neuroectodermal development (noggin and DKK1, respectively) (Lamb et al., 1993; Mukhopadhyay et al., 2001; Anderson et al., 2002); (2) the role of IGF-1 in anterior neural/eye field development (Pera et al., 2001); and (3) Notch pathway inhibition (DAPT_-gamma secretase inhibitor) in photoreceptor cell development (Jadhav et al., 2006). Although retinal differentiation in mouse can be accomplished in 30 days (Tucker et al., 2011, 2013), retinal differentiation of human cells takes significantly longer. During differentiation, these keratinocyte-derived iPSCs formed eyecup-like structures with clearly defined layers of pigmented RPE and non-pigmented neural retina (Figure 2B-E). This was a clear departure from our previous experience with fibroblast-derived iPSCs, which never develop eyecup-like structures under very similar culture conditions. The eyecups began as small pigmented foci that could be detected as early as 45 days post-differentiation (Figure 2B). Following passage and continued differentiation, these pigmented clumps expanded and elongated over 150 days (Figure $2 C$ ) and were eventually joined by 

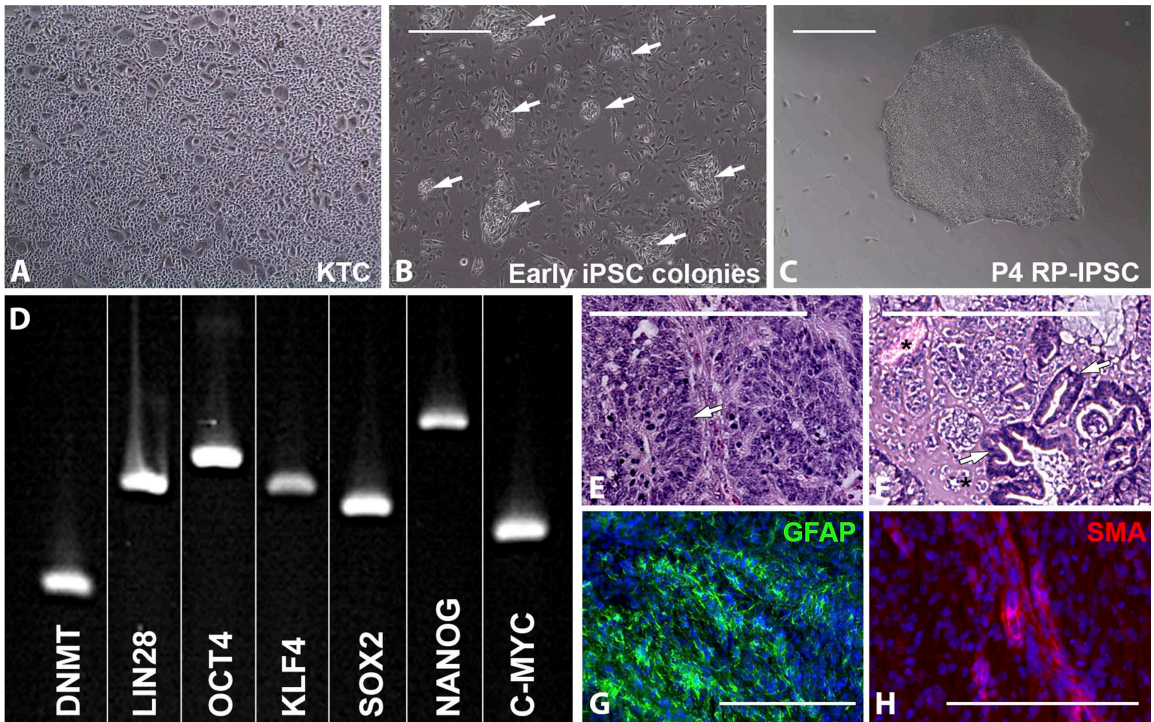

Figure 1. Derivation of iPSCs from keratinocytes of a patient affected with USH2A-associated RP. (A-H) Microscopic analysis of human keratinocytes (A), early keratinocyte-derived iPSC colonies (B, arrows), and purified keratinocyte-derived iPSC cultures (C). At 2-3 weeks post-viral transduction, ES-cell-like iPSC colonies begin to emerge (B, arrows). iPSC colonies isolated, subcultured, and expanded on Synthemax cell culture surfaces maintain a pluripotent morphology (C) express the pluripotency markers DNMT, LIN28, OCT4, KLF4, SOX2, NANOG, and C-MYC (D), and form teratomas consisting of tissues of ectoderm (E, arrow and G, GFAP in green), mesoderm (F, asterisk and $\mathbf{H}$, SMA in red), and endoderm ( $\mathbf{F}$, arrows) each of the three embryonic germ layers $(\mathbf{E}-\mathbf{H})$. Scale bar $=400 \mu \mathrm{m}$. DOI: 10.7554/eLife.00824.003

a clump of neural rosettes (Figure 2C, arrow) on one side of the pigmented structure. In some cases, these RPE/neural units extended into C-shaped eyecup-like structures (Figure 2D,E) while in others, the central cavity did not form and the structure consisted of a circular sheet of neural cells surrounded by a pigmented epithelium (Figure 2-figure supplement 1). In many cases, multiple eyecups at different developmental stages were present within the same well of a differentiating six-well plate (Figure 2D, arrows). The reason that these eyecup-like structures develop in a planar fashion instead of the spheres reported by both Meyer et al. and Eiraku et al. is that we grow these cells under adherent conditions in tissue culture dishes coated with collagen, laminin, and fibronectin, while spheres are grown in suspension (Meyer et alo, 2011; Eiraku and Sasai, 2012). Although there will undoubtedly be advantages of both approaches in different situations, two advantages of this planar system is that the neural cells in the center of the eyecup do not necrose for lack of oxygen, and the firm attachment to the underlying substrate allows homogeneous biopsies to be taken from the eyecups for subculture and analysis.

For example, to explore the cellular makeup of the pigmented layer of the eyecups (Figure 3A), biopsies were taken, gently dissociated, and subcultured for subsequent expansion and microscopic analysis. $24 \mathrm{hr}$ after plating, pigment-containing cell clusters adhered to the culture surface and began to give rise to non-pigmented cells with a fibroblastic morphology (Figure 3B). By $72-96 \mathrm{hr}$ post-plating, extensive cell spreading and a complete loss of pigmentation was noted (Figure 3C). By 2 weeks post-plating, confluent cultures of densely pigmented hexagonal epithelial cells were present (Figure 3D). Immunocytochemical analysis of these cultures revealed cells expressing the tight junction marker ZO1 (Figure 3E), the transcription factor PAX6 (Figure 3F), the RPE-specific channel bestrophin (Figure 3figure supplement 1A) and the RPE visual cycle protein RPE65 (Figure 3-figure supplement 1B). To further investigate the identity of cells within the pigmented layer of patient-specific eyecups, TEM analysis was performed. As shown in Figure 3, cells within the pigmented layer contained pigment granules ( $\mathbf{G}$, asterisks), tight junctions with neighboring cells ( $\mathbf{G}$ and $\mathbf{H}$, arrows), and apical microvilli ( $\mathbf{G}$ and $\mathrm{H}$, arrowheads), all of which are characteristic of native RPE. Collectively, these results indicate that the pigmented layer of cells located at the perimeter of patient-specific eyecups is patient-specific RPE. 

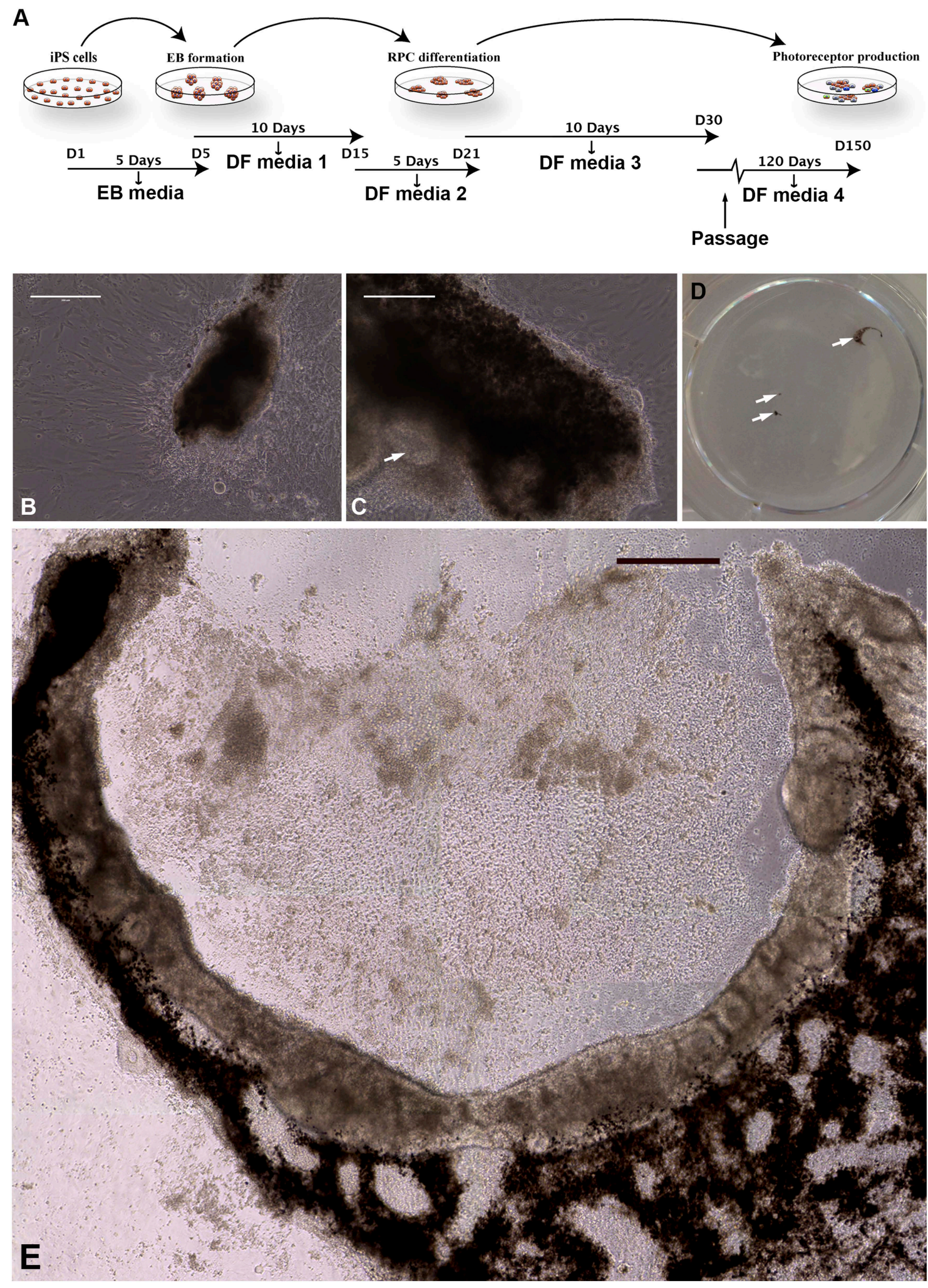

Figure 2. Differentiation of human USH2A-associated iPSCs into eyecup-like structures. (A) Schematic diagram illustrating the differentiation paradigm utilized to generate human eyecup-like structures. (B-E) Morphological analysis of USH2A-associated iPSC-derived eyecups. iPSC-derived eyecups form pigmented cell clumps (B) that extend and wrap in a C shape around newly formed neural rossettes (C). Following this protocol, a typical six-well cell Figure 2. Continued on next page 
Figure 2. Continued

culture dish will have two to four eyecups/well, each at slightly different stages of development (D, arrows, a low magnification image of a typical well of a six-well plate with developing eyecups). At 150 days post-differentiation, complete eyecups with clearly defined neural retina and RPE layers can be identified ( $\mathbf{D}$, top right arrow, and $\mathbf{E})$. Scale bar, $\mathbf{B}$ and $\mathbf{C}=200 \mu \mathrm{m}, \mathbf{D}=400 \mu \mathrm{m}$.

DOI: 10.7554/eLife.00824.004

The following figure supplements are available for figure 2:

Figure supplement 1. Additional examples of human USH2A-associated iPSC-derived eyecup-like structures.

DOI: $10.7554 /$ eLife.00824.005

To determine whether cells contained within non-pigmented neural rosettes (Figure 4A) had adopted a photoreceptor cell fate, patient-specific eyecups were fixed and analyzed with both TEM (Figure 4B) and confocal microscopy using antibodies to the rod photoreceptor markers recoverin and rhodopsin (Figure 4C-E, and Figure 2-figure supplement 1D-F), and recoverin the connecting cilium marker acetylated tubulin (Figure 4F-H). Densely packed neural rosettes contained polarized
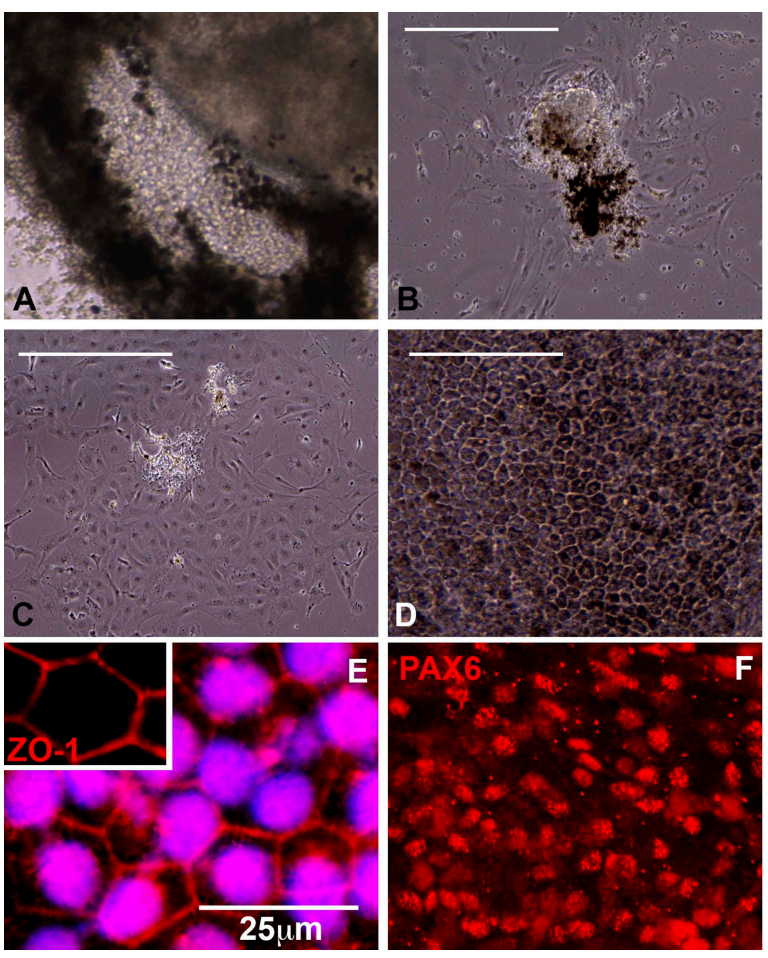

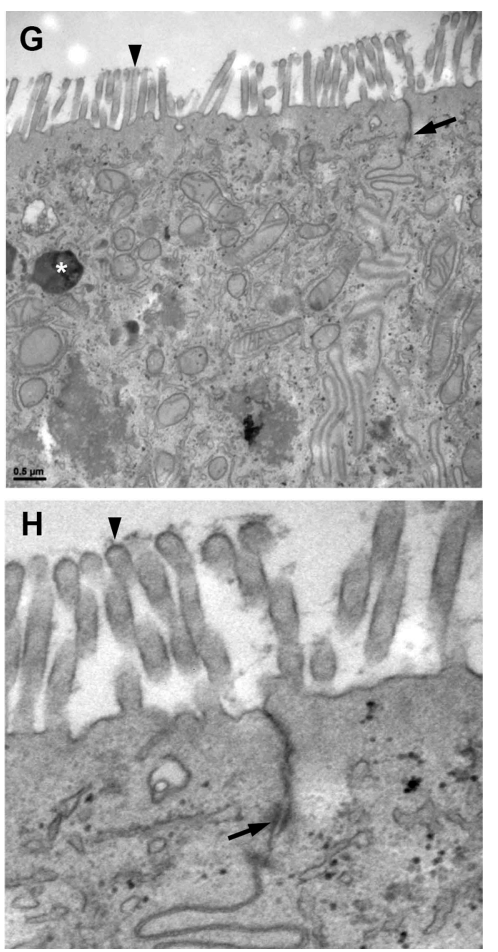

Figure 3. Cells contained within the pigmented layer of USH2A-associated eyecups are of RPE origin. (A) A high magnification phase image of the RPE layer of an USH2A eyecup prior to biopsy and subculture. (B-D) Area of the RPE presented in panel $\mathbf{A}$ was picked and subcultured in fresh RPE culture media on collagen, laminin, and fibronectin coated six-well culture dishes. $24 \mathrm{hr}$ after plating, RPE cells spread and take on a fibroblastic morphology (B). By $72 \mathrm{hr}$ post-plating, RPE cells lose their pigmentation and begin to form cell-cell contacts (C). 2 weeks post-plating, a confluent monolayer of RPE cells are present that have taken on the typical cuboidal RPE morphology and regained pigmentation (D). (E-F) Immunocytochemical analysis of USH2A-associated RPE cells with antibodies targeted against the tight junction marker ZO1 (E) and the transcription factor PAX6 (F). (G-H) TEM analysis of RPE cells within the intact RPE layer of USH2A eyecups ( $\mathbf{H}$ is a high magnification view of the upper right corner of panel G). RPE cells are polarized, have apical microvilli, make tight junctions with neighboring RPE cells ( $\mathbf{G}$ and $\mathbf{H}$, arrows) and contain pigment granules within their cytoplasm (G, asterisk). Scale bar, B-D $=200 \mu \mathrm{m}, \mathbf{G}=0.5 \mu \mathrm{m}$. DOI: 10.7554/eLife.00824.006

The following figure supplements are available for figure 3:

Figure supplement 1. Pigmented cells isolated from USH2A-associated eyecups express bestrophin 1 and RPE65. DOI: 10.7554/eLife.00824.007 

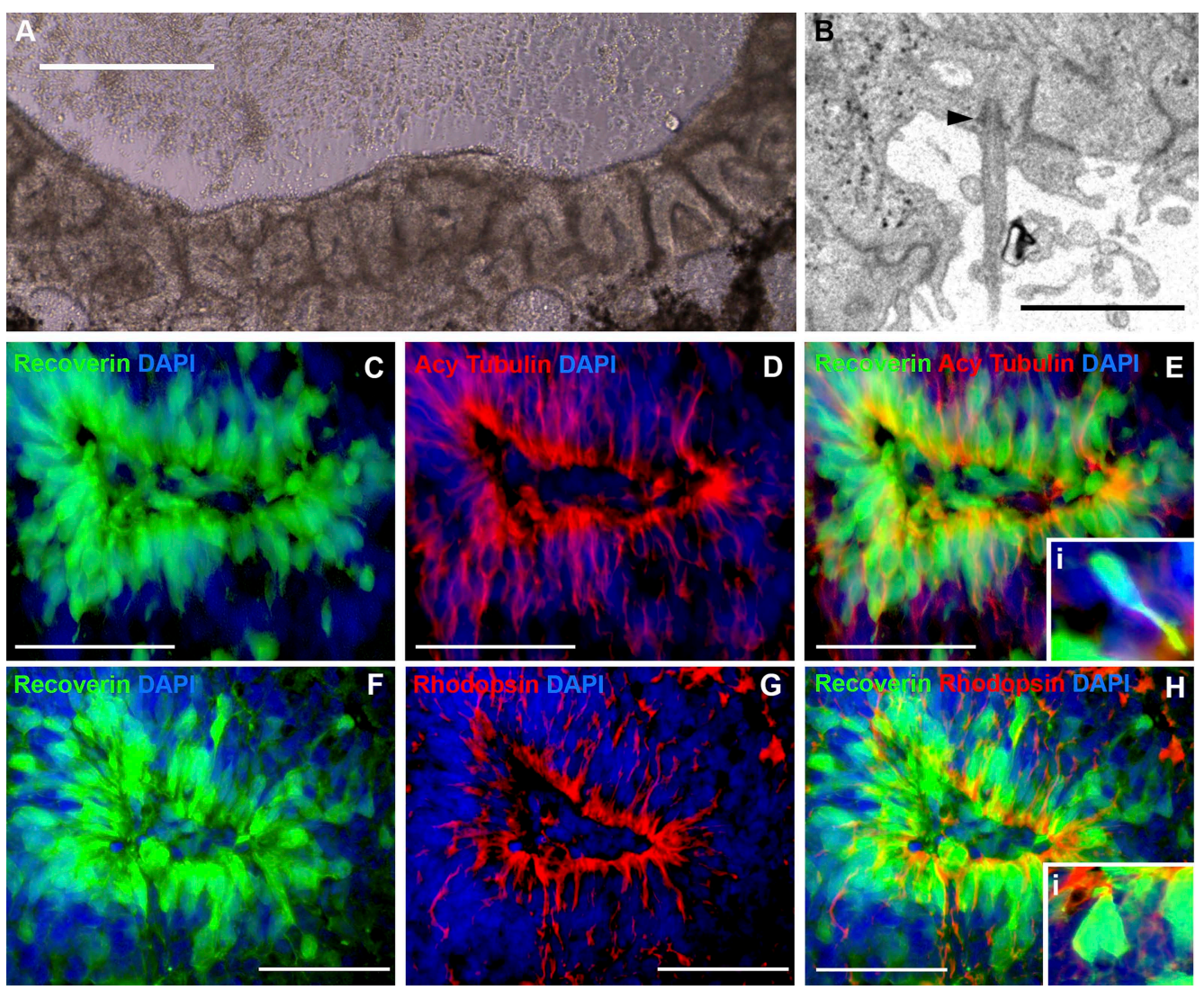

Figure 4. iPSC-derived USH2A-associated neural retinal rosettes consist predominantly of rod photoreceptor cells. (A) Morphological depiction of the neural retina at 120 days post-differentiation. (B) TEM analysis of neural rosettes demonstrates the existence of cilia with clearly identifiable basal bodies. (C-H) Immunocytochemical analysis targeted against the rod photoreceptor markers recoverin and rhodopsin ( $\mathbf{C}-\mathbf{E}$ and $\mathbf{E i}$-high magnification inlay), and the rod photoreceptor marker recoverin and the connecting cilia marker acetylated tubulin ( $\mathbf{F}-\mathbf{H}$ and $\mathbf{H i}$-high magnification inlay). DOI: 10.7554/eLife.00824.008

recoverin positive cells (Figure $4 C, E, F$, and $H$, and Figure 2-figure supplement 1D-F, green) with acetylated tubulin (Figure 4D,E, red) and rhodopsin (Figure 4G,H, and Figure 2-figure supplement $1 D-F$, red) positive structures concentrated at the luminal surface of the rosettes. TEM analysis further confirmed the existence of cilia with clearly identifiable basal bodies (Figure 4B, arrowhead).

In an attempt to determine the developmental timeline of retinal gene expression, a series of rt-PCR and western blot analyses were performed on retinal progenitor cultures isolated at 60,90, and 120 days post-differentiation. The retinal transcripts PAX6, OTX2,CRX, NRL, recoverin, and rhodopsin were detected in differentiating patient-specific iPSCs as early as 60 days post-differentiation (Figure 5A). However, the mature rod photoreceptor protein recoverin and the rod photopigment rhodopsin were not detected until 90 and 120 days post-differentiation, respectively (Figure 5B). Similarly, the cone photopigments blue opsin and red/green opsin were first detected at 90 and 120 days post-differentiation, respectively (Figure $5 B$ ).

To determine whether USH2A was expressed in iPSC-derived neural retina and whether the mutations we identified in the genomic DNA affected the USH2A gene product, rt-PCR analysis of RNA isolated from human control retina, control iPSC-derived photoreceptor precursor cells, and patientspecific iPSC-derived photoreceptor precursor cells were performed. As shown in Figure 6, RNA isolated from patient-specific iPSC-derived photoreceptor precursor cells revealed that the suspected splice site mutation identified in intron 40 of the proband caused exonification of the intron (Figure 6A). Introduction of intronic sequence between exons 40 and 41 results in a frame shift and introduction of a premature stop codon. Similarly, Sanger sequencing of rt-PCR products generated from the iPSC-derived 


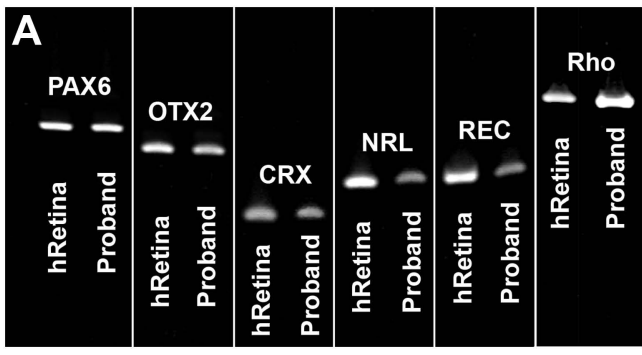

B
Rcvrn
Rho
B Opsin
R/G Opsin
Actin

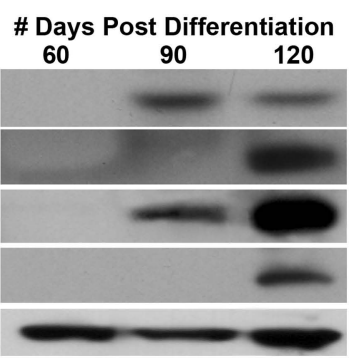

Figure 5. Developmental timeline of neural retina marker expression. (A) RT-PCR analysis of USH2A and human control neural retina for expression of the retinal transcription factors/photoreceptor markers PAX6, OTX2, CRX, NRL, recoverin, and rhodopsin at 60 days post-differentiation. (B) Western blot analysis of USH2A neural retina for expression of the retinal photoreceptor markers recoverin, rhodopsin, blue cone opsin and red/green cone opsin at 60,90 , and 120 days post-differentiation. Although retinal transcripts can be detected as early as 60 days post-differentiation, mature photoreceptor proteins such as recoverin, rhodopsin, and the cone opsins could not be detected until 90 to 120 days post-differentiation.

DOI: 10.7554/eLife.00824.009

photoreceptor precursor cells allowed us to confirm the single point mutation identified within exon 63 of the patients' DNA (Figure 6B). In an attempt to determine the pathophysiological mechanism of these mutations, a series of western blot experiments were performed to look for evidence of mutationinduced apoptosis, ubiquitination, and ER stress. As shown in Figure 6C, when compared to normal human retina, iPSC-derived photoreceptor precursor cells from a normal control and a separate RP patient with known disease-causing mutations and pathophysiology (MAK associated RP caused by nonsense mediated decay of the transcript), the proband was found to have increased expression of the markers GRP78 and GRP94 indicative of protein misfolding and subsequent ER stress (Obeng et al., 2006; Lind et al., 2013).

For patients who have lost the majority of their retinal photoreceptor cells and in turn the majority of their vision, our ultimate goal is to develop a patient-specific autologous cell replacement strategy that can repopulate the outer retina with functional photoreceptors. The ability to transplant such cells into animals with retinal degeneration will also be valuable as part of the vision scientist's armamentarium for exploring the pathophysiologic mechanism of specific mutations that are identified in patients. To test whether patient-specific photoreceptor precursor cells isolated from the neural retina layer of human iPSC-derived eyecups could give rise to new photoreceptor cells in animals for the latter purpose, a series of transplantation experiments were performed. It has been previously shown that the optimal cell type for retinal transplantation is the post-mitotic photoreceptor precursor cell (MacLaren et al., 2006; Pearson et al., 2012). Prior to transplantation, 150-day neural rosettes were dissected free from their surrounding tissues and plated onto fresh tissue culture plates to determine whether these cells would maintain a photoreceptor cell identity following dissociation. To test this, cell cultures were infected 3 days after plating with a lentiviral vector driving expression of GFP under control of the rhodopsin kinase promoter. 2 weeks after plating, post-mitotic rhodopsin kinase positive photoreceptor precursor cells were abundant (Figure 7A,B). In many instances, clusters of the rhodopsin kinase positive cells realigned in a polarized photoreceptor cell fashion and extended axon-like projections (Figure 7B, arrowhead) and outer-segment-like processes (Figure 7B, arrow). Following the confirmation of a stable photoreceptor cell fate, newly generated 150-day photoreceptor precursor cells were transplanted into the subretinal space of P4 immunodeficient $\mathrm{Rag}^{1^{-/-}} \times \mathrm{Crb} 1^{-/-}$mice. $\mathrm{Crb}^{-1-}$ mice were chosen as recipient animals because they exhibit a relatively slow retinal degeneration and also because they are known to be more conducive to cellular integration with proper rod photoreceptor morphology following transplantation than other retinal degenerative strains (Barber et al., 2013).

2 weeks after transplantation, extensive cellular integration was detected using the human Tra1-85 blood antigen as a marker of human cells (Figure 7C-F, Figure 7-figure supplement 1, Sham injection control, red). The integrated cells expressed the mature photoreceptor marker recoverin, extended axonal projections toward the inner plexiform layer (Figure 7D-F arrowheads), and developed 

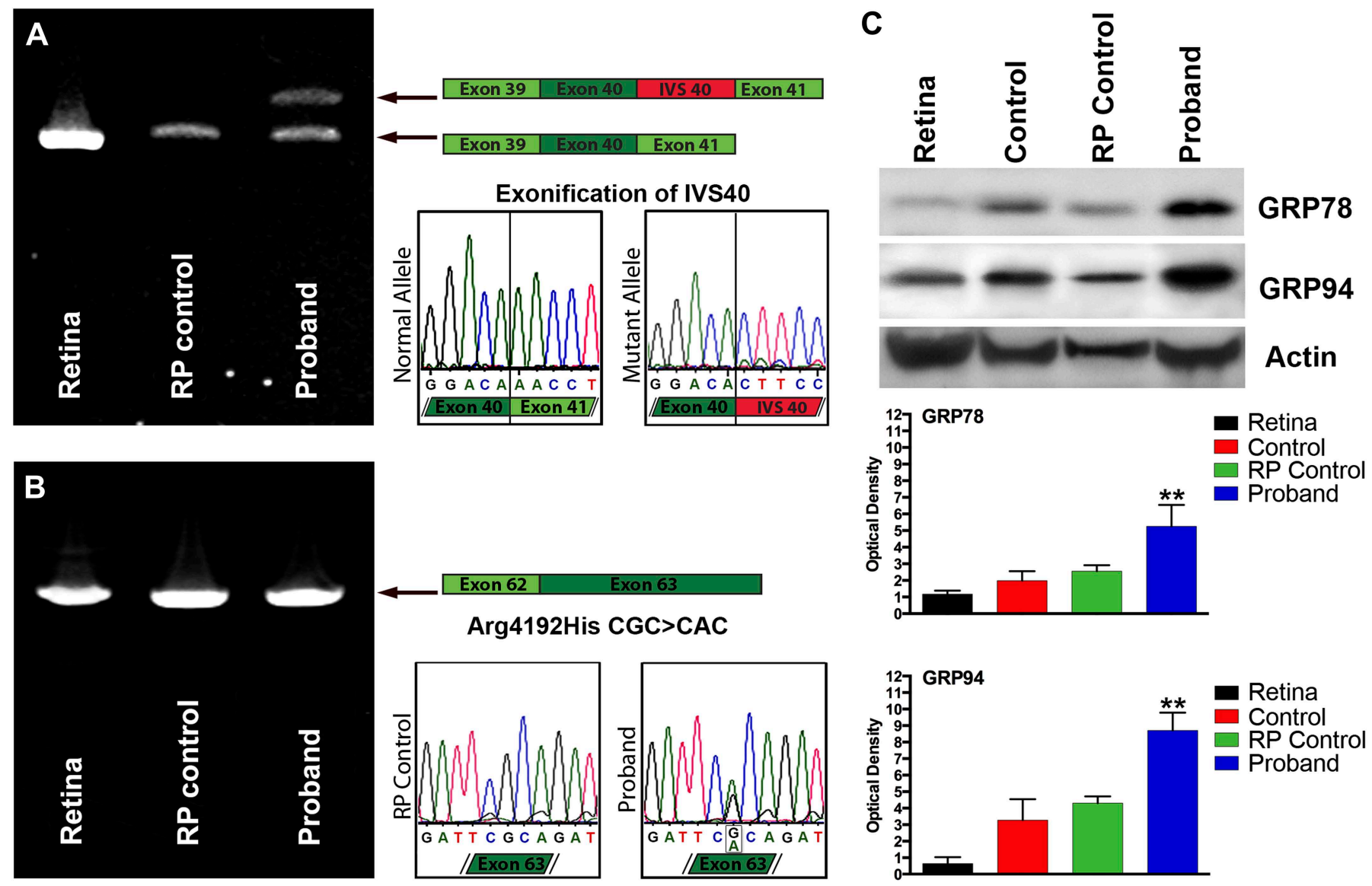

Figure 6. Confirmation of genomic USH2A variants in iPSC-derived neural retina. (A) RT-PCR analysis of USH2A exons 39 to 41 in human control retina (DePristo et al., 2011), human control iPSC-derived neural retina (Baux et al., 2007), and human RP iPSC-derived neural retina. An intronic splice site mutation in intervening sequence 40 of the USH2A gene results in the introduction of a pseudoexon (IVS40 Red) causing a translation frameshift and a premature stop codon. (B) RT-PCR analysis of USH2A exon 62 to 63 in human control human retina (DePristo et al., 2011), human control iPSC-derived neural retina (Baux et al., 2007), and human RP iPSC-derived neural retina. A single heterozygous point mutation identified by whole exome sequencing (Arg4192His) was confirmed in the proband's retinal transcript. (C) Western blot analysis of protein isolated from human control retina and iPSC-derived photoreceptor precursor cells obtained from the proband, an unaffected control, and a separate RP patient with known disease pathophysiology for expression of the ER-stress markers GRP78 and GRP94. Elevated expression of both GRP78 and GRP94 suggests that the mutations identified within the proband result in protein misfolding and ER-stress. ${ }^{* \star} \mathrm{p}<0.001$

DOI: 10.7554/eLife.00824.010

inner- and outer-segment-like projections that extended toward the underlying RPE layer (Figure 7D-F arrows).

\section{Discussion}

Patient-specific iPSC-derived retinal cells are a valuable new tool for investigators seeking to understand and treat degenerative retinal diseases. These cells will allow scientists to explore the pathophysiology of human diseases in ways that were previously possible only in animal models. They will also be useful for evaluating potential therapies ranging from high-throughput screens of small molecule drugs to the comparison of gene replacement constructs containing different promoters or packaged in different vectors. For rare autosomal recessive disorders such as USH2A-associated RP, there is often little statistical evidence for the pathogenicity of one or both of a patient's putative disease-causing mutations. In such cases, iPSC-derived retinal cells may be useful for confirming the pathogenicity of an unusual genotype before embarking upon an invasive therapy like subretinal administration of viral-mediated gene therapy. 

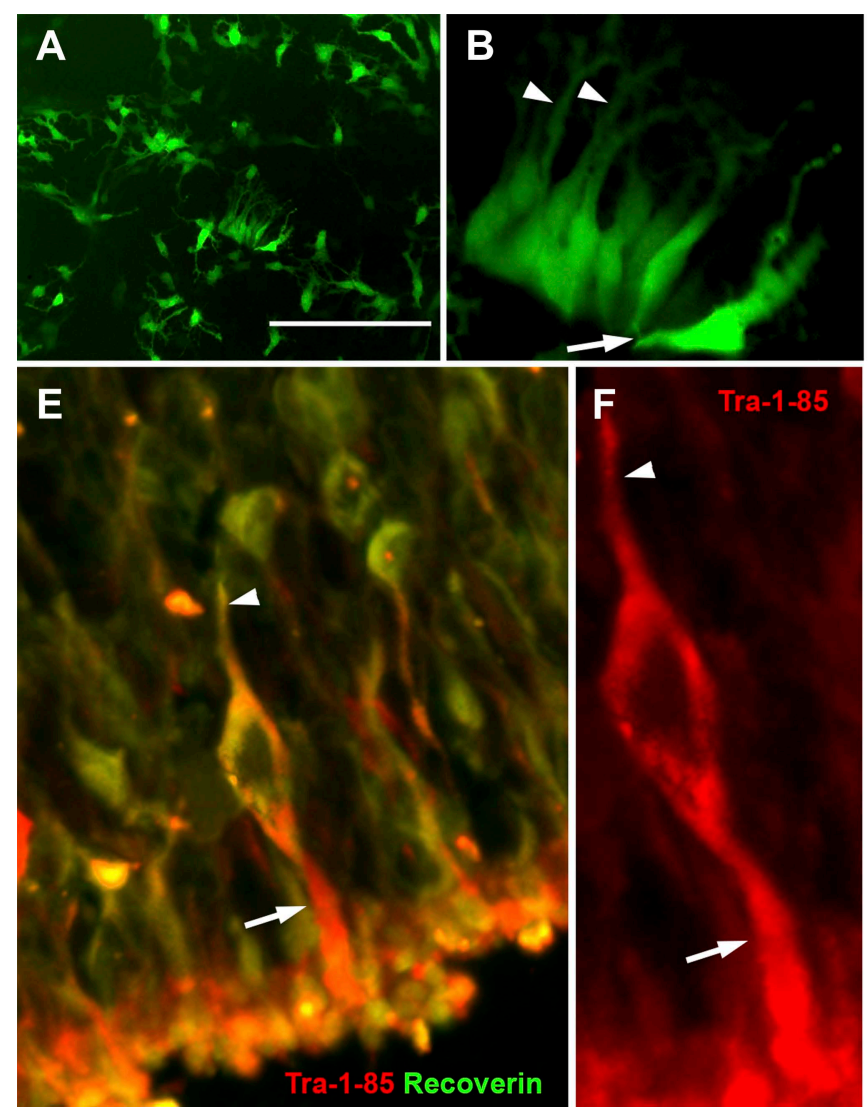
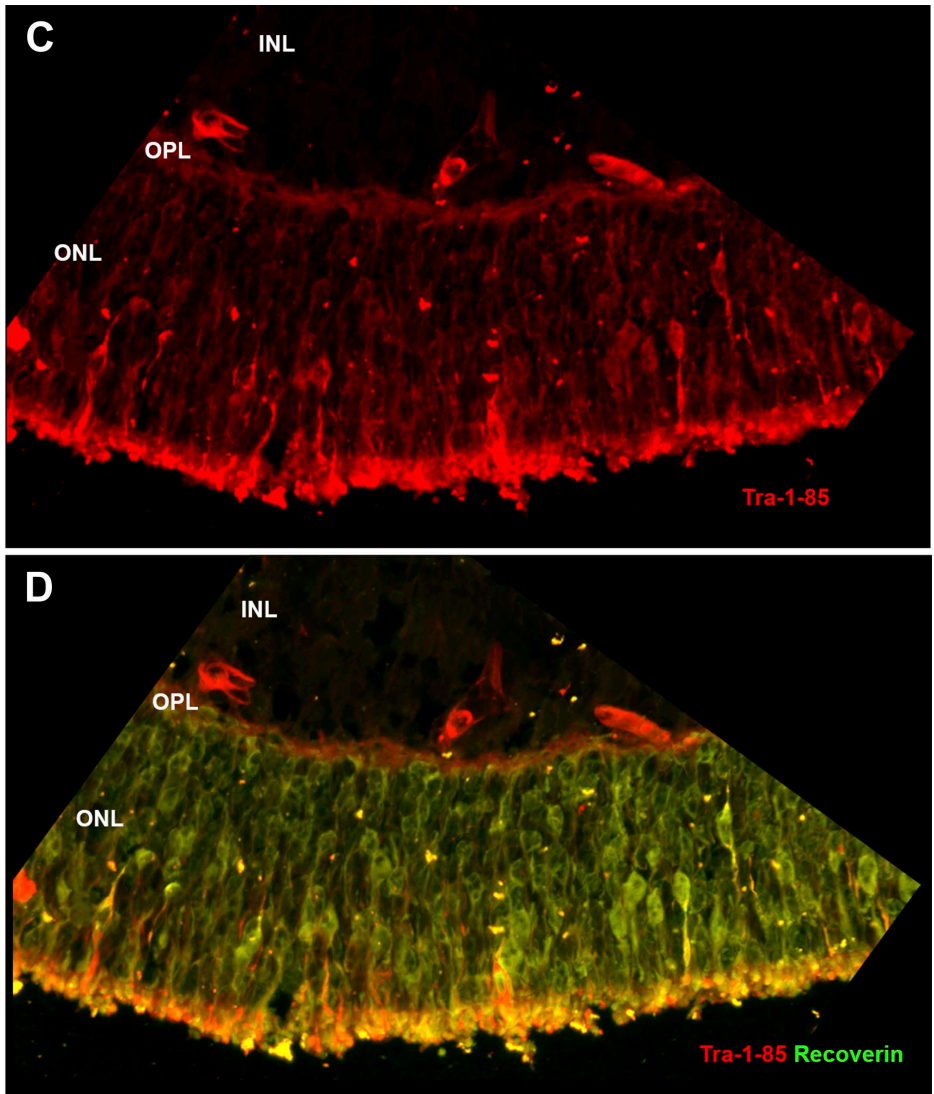

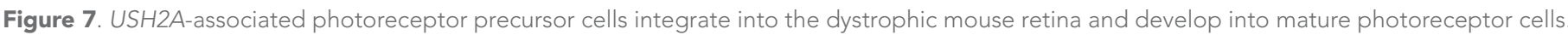

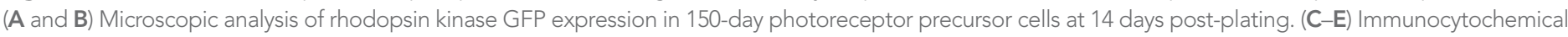

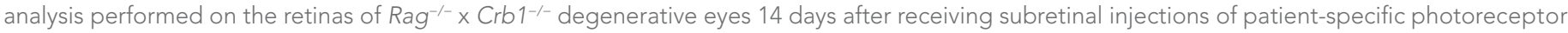
precursor cells targeted against expression of the human cell antigen Tra-1-85 (C-F) and the photoreceptor marker recoverin $(\mathbf{D}$ and $\mathbf{E})$. Scale bar $=50$ m. DOI: 10.7554/eLife.00824.011

The following figure supplements are available for figure 7

Figure supplement 1. USH2A-associated photoreceptor precursor cells integrate into the dystrophic mouse retina

DOI: 10.7554/eLife.00824.012

In this study, we combined sequencing and iPSC technologies to identify and confirm the pathogenicity of disease-causing mutations in an isolated patient with autosomal recessive RP. Exome sequencing of this individual revealed more than 400 plausible disease-causing sequence variations in more than 300 genes. Two of these were present in genes known to cause autosomal recessive RP (an Arg4192His variant in USH2A and a Thr1428Met in ABCA4), but a second disease-causing allele could not be found in either of these genes despite Sanger sequencing of the entire coding sequence. We were fortunate that Vaché et al. identified and reported the USH2A variant in IVS 40 that proved to be our patient's second disease-causing allele. Non-exomic mutations are not an uncommon cause of recessive diseases. In some instances (e.g., CEP290-associated LCA) they account for the largest proportion of diseasecausing alleles (Stone, 2007). As the iPSC technology becomes more routine, the evaluation of RNA from iPSC-derived retina may become a common step in the analysis of exome sequencing data when two clearly disease-causing alleles cannot be identified in known disease genes. To confirm the pathogenicity of the USH2A variants we observed in our patient, USH2A transcripts were analyzed using RNA isolated from iPSC-derived photoreceptor precursor cells obtained from the proband, an unaffected control and human donor retina. The suspected splice site mutation within IVS40 was shown to cause exonification of the intron, a translation frameshift and a premature stop codon. The transcription of the patient's USH2A missense mutation was confirmed in a similar fashion. In combination, these mutations 
resulted in an upregulation of the markers GRP78 and GRP94 indicative of protein misfolding and subsequent ER stress.

Following transplantation into neonatal retinal degenerative Crb1 mutant mice, our patient's photoreceptor precursor cells integrated into the outer nuclear layer and differentiated into morphologically and immunohistochemically recognizable photoreceptors. This finding is compatible with our patient's history of normal vision until the third decade of life; that is, his USH2A mutations do not appear to cause a gross developmental abnormality of photoreceptor cells. It is also noteworthy that transplantable photoreceptor precursor cells could be generated from the skin of a patient in the seventh decade of life. The transplantation of photoreceptor precursor cells derived from early postnatal retina or embryonic stem cells has been accomplished before by other groups (MacLaren et al., 2006; La Torre et al., 2012; Pearson et al., 2012), but to our knowledge, this is the first time that photoreceptor precursor cells have been derived from an adult human RP patient and successfully transplanted into mice. However, much work remains to be done before such transplants could be considered evidence for the feasibility of sight-restoring iPSC-derived treatments in humans. For example, synaptic connectivity will need to be demonstrated ultrastructurally and electrophysiologically, and useful vision in treated animals will need to be demonstrated with an array of psychophysical approaches. Longevity of the transplanted cells will be important to demonstrate as will the cells' lack of tumorigenicity. For such transplants to have practical clinical utility it will also be important to show that the transplanted cells can integrate and function in the retinas of animals with advanced stages of many different molecular types of retinal degeneration.

Unlike many of the genes targeted in current clinical trials, USH2A is very large and will be impossible to package into the viral vectors in current clinical use. The coding sequence of USH2A is $>18 \mathrm{~kb}$, and the packaging limits of AAV and EIAV vectors are about $3 \mathrm{~kb}$ and $10 \mathrm{~kb}$, respectively. For genes such as USH2A, vectors with large carrying capacities such as HSV1, which can accommodate inserts of up to $40 \mathrm{~kb}$ in size (Thomas et al., 2003), may be useful. In addition to the vector limitations, the proper stoichiometry of the delivered message will also be critical for some genes. It is possible that patients like the one reported here, with a truncated protein encoded by one allele and a misfolded protein encoded by the other, may require a different promoter and multiplicity of infection than a different patient who harbors two stop mutations in USH2A. Patient-specific iPSC-derived retinal cells may be useful in choosing the optimal gene therapy strategy for each individual.

For late-stage USH2A-associated RP where significant photoreceptor cell loss has occurred, cell replacement strategies will be required to restore vision. In some cases, correcting the genetic defect responsible for the photoreceptor degeneration will be necessary before transplanting photoreceptor cells into the patient. The development of site specific TALEN- or CRISPR-based genome editing approaches, which allow for the targeted correction of patient-specific cells in vitro, is proving to have great utility for endogenous gene correction (Hockemeyer et al., 2011; Ding et al., 2013; Wang et alo, 2013). For instance, Hockemeyer et al. recently demonstrated that for the five genomic sites targeted, pluripotent iPSC clones carrying transgenes solely at TALEN-specified loci could be obtained (Hockemeyer et al., 2011). Similarly using the CRISPR/CAS-9 system, Wang et al. recently demonstrated the ability to simultaneously manipulate five separate genetic loci in mouse ES cells (Wang et al., 2013). A major advantage of these approaches is that unlike exogenous gene addition in which promoter strength and multiplicity of infection may require patient-specific adjustment, TALEN- and CRISPR-mediated correction have the advantage that the gene remains under the control of the endogenous promoter. For recessive diseases such as USH2A-associated RP, correction of a single disease-causing allele should be sufficient for a therapeutic effect. One could test this directly by transplanting corrected cells into retinal degenerative mice and determining whether cells with both alleles corrected behave differently than those with one or neither allele corrected.

It is possible that for some individuals with late-onset disease, such as the patient described in this report, genetic correction prior to transplantation may not be required. That is, if the patient's native photoreceptor cells develop and function normally until the third decade of life, as suggested by our current data and the patient's clinical history, it is possible that replacement of lost photoreceptors with iPSCs that have not been genetically modified could be a reasonably durable treatment.

An alternative approach to patient-specific autologous cell replacement that would also not require genetic manipulation of the donor cell population prior to delivery would be the use of either genetically unmatched ES or tissue-specific precursor cells. This approach is currently in clinical trial for the treatment of Stargardt macular dystrophy and age-related macular degeneration (AMD) (Schwartz et al., 2012). 
In these studies, ES cell-derived retinal-pigmented epithelial cells are delivered to immune suppressed patients as subretinal bolus cell injections (Schwartz et al., 2012). However, there are considerable disadvantages to using allogeneic cells. Retinas injured by inherited disease often have a loss of integrity of the blood retinal barrier, which would allow the patient's peripheral immune system access to the transplanted cells. This type of transplant approach would likely require life-long immunomodulation, (Hambright et alo, 2012) putting patients at further risk.

In summary, by combining next-generation and Sanger sequencing with iPSC technologies we were able to demonstrate the pathogenicity of two disease-causing mutations in a patient with non-syndromic USH2A-associated RP. We also demonstrated that keratinocytes cultured from a patient in the seventh decade of life can be reprogrammed into iPSCs and differentiated into a multi-layered eyecup-like structure with immunohistochemical and ultrastructural features of human retinal precursor cells. Finally, we showed that these patient-derived retinal precursor cells have the ability to integrate into the developing mouse retina and to form morphologically and immunohistochemically recognizable photoreceptor cells. These findings will enable patient-specific studies of disease mechanism, gene correction, and photoreceptor cell transplantation for many different types of human retinal degeneration.

\section{Materials and methods}

\section{Ethics statement}

All experiments were conducted with the approval of the University of lowa Animal Care and Use Committee (Animal welfare assurance \#1009184) and the University of lowa Internal Review Board (IRB \# 200202022). All experiments were consistent with the ARVO Statement for the Use of Animals in Ophthalmic and Vision Research and the Treaty of Helsinki.

\section{Patient-derived cells}

After informed consent, skin biopsies were collected from a 62-year-old patient with an unknown cause of RP, three patients with known causes of retinal disease and three individuals without eye disease, and these were used for fibroblast and keratinocyte isolation (as described previously [Bickenbach, 2005; Tucker et al., 2013]). Cells were expanded and targeted for iPSC generation.

\section{iPSC generation}

iPSCs were generated from human patient-specific keratinocytes via infection with four separate nonintegrating Sendai viruses, each of which were designed to drive expression of one of four transcription factors: OCT4, SOX2, KLF4, and c-MYC (A1378001, Invitrogen, Grand Island, NY). Keratinocytes plated on six-well tissue culture plates were infected at an $\mathrm{MOI}$ of 5. At 12-16 hr post-infection, cells were washed and fed with fresh growth media (Epilife media with keratinocyte supplement [Invitrogen] and $0.2 \%$ primocin [Invivogen]). At 7 days post-infection, cells were passaged onto six-well Synthemax cell culture dishes at a density of 300,000 cells/well and fed every day with pluripotency media (DMEM F-12 media [Gibco], 20\% knockout serum replacement [Gibco], 0.0008\% beta-mercaptoethanol [Sigma-Aldrich, St. Louis, MO], 1\% $100 \times$ NEAA [Gibco], 100 ng/ml bFGF [human] [R\&D], and 0.2\% primocin [Invivogen]. At 3 weeks post-viral transduction, iPSC colonies were picked, passaged, and clonally expanded on fresh Synthemax plates. During reprogramming and maintenance of pluripotency, cells were cultured at $5 \% \mathrm{CO}_{2}, 5 \% \mathrm{O}_{2}$, and $37^{\circ} \mathrm{C}$.

\section{iPS cell differentiation}

To maintain pluripotency, adult-derived iPSCs were cultured in xeno/feeder free cell culture media. To initiate differentiation, iPSCs were removed from the culture substrate via manual passage using Stem Passage manual passage rollers (Invitrogen), resuspended in embryoid body (EB) media (DMEM F-12 media [Gibco] containing 10\% knockout serum replacement [Gibco], 2\% B27 supplement [Gibco], 1\% N2 supplement [Gibco], 1\% L-glutamine [Gibco], 1\% $100 \times$ NEAA [Gibco], 0.2\% primocin [Invivogen], $1 \mathrm{ng} / \mathrm{ml}$ noggin [R\&D Systems, Minneapolis, MN], $1 \mathrm{ng} / \mathrm{ml}$ Dkk-1 [R\&D Systems], $1 \mathrm{ng} / \mathrm{ml}$ IGF-1 [R\&D Systems], and $0.5 \mathrm{ng} / \mathrm{ml} \mathrm{bFGF} \mathrm{[R \& D} \mathrm{Systems]),} \mathrm{and} \mathrm{plated} \mathrm{at} \mathrm{a} \mathrm{density} \mathrm{of} \sim 50$ cell clusters $/ \mathrm{cm}^{2}$ on ultra low adhesion culture plates (Corning, Lowell, MA). Cell clusters were cultured for 5 days as indicated above, after which the EBs were removed, washed, and plated at a density of $25-30 \mathrm{EBs} / \mathrm{cm}^{2}$ in fresh differentiation media 1 (DMEM F-12 media [Gibco], 2\% B27 supplement [Gibco] 1\% N2 supplement [Gibco], 1\% L-glutamine [Gibco], 1\% $100 \times$ NEAA [Gibco] $10 \mathrm{ng} / \mathrm{ml}$ noggin [R\&D Systems], $10 \mathrm{ng} / \mathrm{ml}$ Dkk-1 [R\&D Systems], $10 \mathrm{ng} / \mathrm{ml} \mathrm{IGF-1} \mathrm{[R \& D} \mathrm{Systems]} \mathrm{and} 1 \mathrm{ng} / \mathrm{ml}$ bFGF [R\&D Systems]) in six-well 
Synthemax culture plates. Cultures were fed every other day for 10 days with differentiation media 1. For the following 6 days, cultures were fed with differentiation media 2 (differentiation media $1+10 \mu \mathrm{M}$ of the Notch signaling inhibitor, DAPT [Calbiochem, Gibbstown, NJ]). For the following 12 days, cultures were fed with differentiation media 3 (differentiation media $2+2 \mathrm{ng} / \mathrm{ml}$ of aFGF [R\&D Systems]). To enhance pigmentation and eyecup-like structure formation, cells were passaged at day 50-70 in fresh cell culture plates coated as described above and cultured for up to 150 days in differentiation media 4 (DMEM F-12 media [Gibco], 2\% B27 supplement [Gibco] 1\% N2 supplement [Gibco], 1\% L-glutamine [Gibco], $1 \% 100 \times$ NEAA [Gibco]).

\section{Teratoma formation}

To validate that generated iPSCs were pluripotent, teratomas were generated by IM injection of $2.5 \times 10^{6}$ undifferentiated iPSCs into immunodeficient (SCID) mice. After 90 days, tumors were excised, fixed, paraffin embedded, and sectioned.

\section{Histology}

Teratomas were fixed in $10 \%$ formalin for $24 \mathrm{hr}$ prior to dehydration and mounting in paraffin wax (VWR). Samples were sectioned at $6 \mu \mathrm{m}$ and H\&E staining was performed using standard protocols.

\section{Immunostaining}

Cells were fixed in a $4 \%$ paraformaldehyde solution and immunostained as described previously (Tucker et alo, 2010, 2011, 2013). Briefly, cells/tissues were incubated overnight at $4^{\circ} \mathrm{C}$ with antibodies targeted against either GFAP (MAB360; Millipore, Billerica, MA) or aSMA (ab5694; Abcam, Cambridge, MA) for teratoma formation or ZO-1 (MABT11; Millipore), PAX6 (MAB5552; Millipore), bestrophin 1 (AB14929; Abcam), RPE65 (MAB5428; Millipore), acetylated tubulin (t7451; Sigma Aldrich), recoverin (AB5585; Millipore), and rhodopsin (MAB5316; Millipore) for retinal differentiation. Subsequently, Cy2- or Cy3-conjugated secondary antibodies were used (Jackson Immunochem, West Grove, PA), and the samples were analyzed using confocal microscopy. Microscopic analysis was performed such that exposure time, gain, and depth of field remained constant between experimental conditions.

\section{Transmission electron microscopy (TEM)}

Eyecups at 150 days post-differentiation were fixed in one half strength Karnovsky fixative as described previously (PMID 17591911), followed by osmication, dehydration, and embedment in Epon resin. All procedures took place in the tissue culture dish. After polymerization, blocks were removed and trimmed, ultrathin sections were collected on formvar coated grids, and samples were imaged on a JEOL JEM1230 transmission electron microscope.

\section{Immunoblotting}

For Western blot analysis, undifferentiated and differentiated iPSCs were homogenized in lysis buffer (50 mM Tris- $\mathrm{HCl}, \mathrm{pH} 7.6,150 \mathrm{mM} \mathrm{NaCl}, 10 \mathrm{mM} \mathrm{CaCl} 2,1 \%$ triton X-100, 0.02\% $\mathrm{NaN}_{3}$, [Sigma-Aldrich]) and centrifuged. Supernatants were isolated and protein concentrations determined using a BCA protein assay (Pierce Chemicals, Rockford, IL). Equivalent amounts of protein $(50 \mu \mathrm{g})$ were subjected to SDS-PAGE (8-10\% acrylamide), transferred to PVDF, and probed with primary antibodies targeted against recoverin (AB 5585; EMD Millipore), rhodopsin (MAB5316; EMD Millipore), blue opsin (AB5407; EMD Millipore), red/green opsin (AB5405; EMD Millipore), GRP 78 (SC-376768; Santa Cruz), GRP 94 (SC-53929; Santa Cruz) and Actin (AB20272; Abcam; used as a loading control). Blots were visualized with ECL reagents (GE healthcare, Piscataway, NJ) and exposed to X-ray film (Fisher, Pittsburg, PA).

\section{RNA isolation and rt-PCR}

Total RNA was extracted using the RNeasy Mini-kit (Qiagen, Valencia, CA) following the provided instructions. Briefly, cells were lysed, homogenized, and ethanol was added to adjust binding conditions. Samples were spun using RNeasy spin columns, washed, and RNA was eluted using RNase-free water. $1 \mu \mathrm{g}$ of RNA was reverse transcribed into cDNA using the random hexamer (Invitrogen, Carlsbad, CA) priming method and Omniscript reverse transcriptase (Qiagen). All PCR reactions were performed in a $40 \mu$ reaction containing $1 \times$ PCR buffer, $1.5 \mathrm{mM} \mathrm{MgCl} 2,0.2 \mathrm{mM}$ dNTPs, $100 \mathrm{ng}$ of DNA, $1.0 \mathrm{U}$ of AmpliTaq Gold (Applied Biosystems, Foster City, CA) and 20 pmol of each gene-specific primer. All cycling profiles incorporated an initial denaturation temperature of $94^{\circ} \mathrm{C}$ for $10 \mathrm{~min}$ followed by 35 amplification cycles with the following conditions, $30 \mathrm{~s}$ at $94^{\circ} \mathrm{C}, 30 \mathrm{~s}$ at annealing temperature of 
each primer, and $1 \mathrm{~min}$ at $72^{\circ} \mathrm{C}$ with a final extension at $72^{\circ} \mathrm{C}$ for $10 \mathrm{~min}$. $\mathrm{PCR}$ products were separated by electrophoresis on 2\% agarose gels (Invitrogen). Gene-specific primers (Invitrogen) are given in Supplementary file $1 \mathrm{~A}$.

\section{DNA extraction}

Blood samples were obtained from all subjects. DNA was extracted by following the manufacturers specifications for whole blood DNA extraction using Gentra Systems' Autopure LS instrument.

\section{Exon capture}

Targeted enrichment of exons was performed using the Agilent SureSelect All Exon Capture platform per manufacturer's instructions. This capture platform includes $38 \mathrm{Mb}$ of targeted features.

\section{Next-generation DNA sequencing}

Sequencing of the captured genomic DNA was performed following the manufacturer's instructions on an Illumina HiSeq sequencer at the Hudson Alpha Institute in Huntsville, Alabama.

\section{Automated DNA sequencing}

Variants detected by next-generation sequencing were confirmed using automated Sanger sequencing using dye termination chemistry on an $\mathrm{ABI} 3730$ sequencer. All sequencing was bi-directional.

\section{Transplantation}

Newly generated 150-day photoreceptor precursor cells were transplanted into the subretinal space of P4 immune compromised Rag $1^{-/-} \times \mathrm{Crb}^{1--}$ mice. 2 weeks after transplantation, mice were sacrificed and eyes were removed for histological analysis, fixed in $4 \%$ paraformaldehyde for $12 \mathrm{hr}$, embedded and sectioned on a cryostat. Sectioned mouse eyes were used for immunofluorescence analysis. Sections were blocked in 10\% goat serum 3\% BSA and $0.2 \%$ triton X-100 for $1 \mathrm{hr}$, and then incubated with anti-Tra-1-85 (MAB4385; Millipore), and recoverin antibodies (AB5585; Millipore) followed by visualization with Cy2- and Cy3-conjugated secondary antibodies (Jackson Immunochem, West Grove, PA). Sections were assessed by confocal microscopy.

\section{Additional information}

Funding

\begin{tabular}{lll} 
Funder & $\begin{array}{l}\text { Grant reference } \\
\text { number }\end{array}$ & Author \\
\hline $\begin{array}{l}\text { Howard Hughes Medical } \\
\text { Institute }\end{array}$ & & Edwin M Stone \\
\hline $\begin{array}{l}\text { NIH Directors New } \\
\text { Innovator Award }\end{array}$ & 1-DP2-OD007483-01 & Budd A Tucker \\
\hline National Eye Institute & EY017451 & Robert F Mullins, Edwin M Stone \\
\hline $\begin{array}{l}\text { Foundation Fighting } \\
\text { Blindness }\end{array}$ & Budd A Tucker, Edwin M Stone \\
\hline $\begin{array}{l}\text { Stephen A Wynn } \\
\text { Foundation }\end{array}$ & $\begin{array}{l}\text { Budd A Tucker, Robert F Mullins, } \\
\text { Edwin M Stone }\end{array}$ \\
\hline $\begin{array}{l}\text { Grousbeck Family } \\
\text { Foundation }\end{array}$ & $\begin{array}{l}\text { Budd A Tucker, Robert F Mullins, } \\
\text { Edwin M Stone }\end{array}$ \\
\hline $\begin{array}{l}\text { Leo, Jacques and Marion } \\
\text { Hauser Family Vision } \\
\text { Restoration Fund }\end{array}$ & $\begin{array}{l}\text { Budd A Tucker, Robert F Mullins, } \\
\text { Edwin M Stone }\end{array}$ \\
\hline
\end{tabular}

The funders had no role in study design, data collection and interpretation, or the decision to submit the work for publication.

Author contributions

BAT, RFM, EMS, Conception and design, Acquisition of data, Analysis and interpretation of data, Drafting or revising the article, Contributed unpublished essential data or reagents; LMS, Acquisition of data, Contributed unpublished essential data or reagents; KA, MEE, EK, MJR, AVD, TAB, Acquisition of data, Drafting or revising the article 
Ethics

Human subjects: All experiments were conducted with the approval of the University of lowa Internal Review Board (IRB \# 200202022). All subjects provided written informed consent for this research study, which was approved by the Institutional Review Boards of the participating centers and adhered to the tenets set forth in the Declaration of Helsinki.

Animal experimentation: All experiments were conducted with the approval of the University of lowa Animal Care and Use Committee (Animal welfare assurance \#1009184).

\section{Additional files}

Supplementary files

- Supplementary file 1. (A) Prioritization of exome variants. (B) Gene-specific primer sequences used for rt-PCR. $F=$ forward primer and $\mathrm{R}=$ reverse primer.

DOI: $10.7554 /$ Life.00824.013

Major datasets

The following previously published datasets were used:

\begin{tabular}{lllll}
\hline Author(s) & Year & Dataset title & Dataset ID and/or URL & $\begin{array}{l}\text { Database, license, and } \\
\text { accessibility information }\end{array}$ \\
\hline $\begin{array}{l}\text { The } 1000 \text { Genomes } \\
\text { Project Consortium }\end{array}$ & 2012 & $\begin{array}{l}\text { Sequence Reads- } \\
\text { All Exomes }\end{array}$ & $\begin{array}{l}\text { ftp://ftp-trace.ncbi.nih. } \\
\text { gov/1000genomes/ftp/ } \\
\text { data/ }\end{array}$ & $\begin{array}{l}\text { Instructions on accessing data } \\
\text { at the 1000 Genomes website: } \\
\text { http://www.1000genomes. } \\
\text { org/data\#DataAccess. }\end{array}$ \\
\hline $\begin{array}{l}\text { NHLBI GO Exome } \\
\begin{array}{l}\text { Sequencing Project } \\
\text { (ESP) }\end{array}\end{array}$ & 2012 & $\begin{array}{l}\text { Exome Variant } \\
\text { Server }\end{array}$ & $\begin{array}{l}\text { ESP-6500SI; http://evs.gs. } \\
\text { washington.edu/EVS/ } \\
\text { (Version 2) }\end{array}$ & $\begin{array}{l}\text { Used release dated October } \\
31,2012 ; \text { current release } \\
\text { available from http://evs.gs. } \\
\text { washington.edu/EVS/. }\end{array}$
\end{tabular}

\section{References}

Aasen T, Raya A, Barrero MJ, Garreta E, Consiglio A, Gonzalez F, et al. 2008. Efficient and rapid generation of induced pluripotent stem cells from human keratinocytes. Nat Biotechnol 26:1276-84. doi: 10.1038/nbt.1503.

Aller E, Jaijo T, Beneyto M, Nájera C, Oltra S, Ayuso C, et al. 2006. Identification of 14 novel mutations in the long isoform of USH2A in Spanish patients with Usher syndrome type II. J Med Genet 43:e55. doi: 10.1136/ jmg.2006.041764.

Anderson RM, Lawrence AR, Stottmann RW, Bachiller D, Klingensmith J. 2002. Chordin and noggin promote organizing centers of forebrain development in the mouse. Development 129:4975-87.

Barber AC, Hippert C, Duran Y, West EL, Bainbridge JWB, Warre-Cornish K, et al. 2013. Repair of the degenerate retina by photoreceptor transplantation. Proc Natl Acad Sci USA 110:354-9. doi: 10.1073/pnas.1212677110.

Barrero MJ, Berdasco M, Paramonov I, Bilic J, Vitaloni M, Esteller M, et al. 2012. DNA hypermethylation in somatic cells correlates with higher reprogramming efficiency. Stem Cells 30:1696-702. doi: 10.1002/stem.1138.

Baux D, Larrieu L, Blanchet C, Hamel C, Ben Salah S, Vielle A, et al. 2007. Molecular and in silico analyses of the full-length isoform of usherin identify new pathogenic alleles in Usher type II patients. Hum Mutat 28:781-9. doi: 10.1002/humu.20513.

Bickenbach JR. 2005. Isolation, characterization, and culture of epithelial stem cells. Methods Mol Biol 289:97-102. doi: 10.1385/1-59259-830-7:097.

Cheng Z, Ito S, Nishio N, Xiao H, Zhang R, Suzuki H, et al. 2011. Establishment of induced pluripotent stem cells from aged mice using bone marrow-derived myeloid cells. J Mol Cell Biol 3:91-8. doi: 10.1093/jmcb/mjq044.

DePristo MA, Banks E, Poplin R, Garimella KV, Maguire JR, Hartl C, et al. 2011. A framework for variation discovery and genotyping using next-generation DNA sequencing data. Nat Genet 43:491-8. doi: 10.1038/ng.806.

Ding Q, Lee Y-K, Schaefer EAK, Peters DT, Veres A, Kim K, et al. 2013. A TALEN genome-editing system for generating human stem cell-based disease models. Cell Stem Cell 12:238-51. doi: 10.1016/j.stem.2012.11.011.

Eiraku M, Sasai Y. 2012. Mouse embryonic stem cell culture for generation of three-dimensional retinal and cortical tissues. Nat Protoc 7:69-79. doi: 10.1038/nprot.2011.429.

Hambright D, Park K-Y, Brooks M, McKay R, Swaroop A, Nasonkin IO. 2012. Long-term survival and differentiation of retinal neurons derived from human embryonic stem cell lines in un-immunosuppressed mouse retina. Mol Vis 18:920-36.

Hirami Y, Osakada F, Takahashi K, Okita K, Yamanaka S, Ikeda H, et al. 2009. Generation of retinal cells from mouse and human induced pluripotent stem cells. Neurosci Lett 458:126-31. doi: 10.1016/j.neulet.2009.04.035.

Hockemeyer D, Wang H, Kiani S, Lai CS, Gao Q, Cassady JP, et al. 2011. Genetic engineering of human pluripotent cells using TALE nucleases. Nat Biotechnol 29:731-4. doi: 10.1038/nbt.1927. 
Homer N, Merriman B, Nelson SF. 2009. BFAST: an alignment tool for large scale genome resequencing. PLOS ONE 4:e7767. doi: 10.1371/journal.pone.0007767.

Homma K, Okamoto S, Mandai M, Gotoh N, Rajasimha HK, Chang Y-S, et al. 2013. Developing rods transplanted into the degenerating retina of $\mathrm{Crx}$-knockout mice exhibit neural activity similar to native photoreceptors. Stem Cells 31:1149-59. doi: 10.1002/stem.1372.

Hu Q, Friedrich AM, Johnson LV, Clegg DO. 2010. Memory in induced pluripotent stem cells: reprogrammed human retinal-pigmented epithelial cells show tendency for spontaneous redifferentiation. Stem Cells 28:1981-91. doi: 10.1002/stem.531.

Jadhav AP, Mason HA, Cepko CL. 2006. Notch 1 inhibits photoreceptor production in the developing mammalian retina. Development 133:913-23. doi: 10.1242/dev.02245.

Jin Z-B, Okamoto S, Xiang P, Takahashi M. 2012. Integration-free induced pluripotent stem cells derived from retinitis pigmentosa patient for disease modeling. Stem Cells Trans/ Med 1:503-9. doi: 10.5966/ sctm.2012-0005.

Judson RL, Babiarz JE, Venere M, Blelloch R. 2009. Embryonic stem cell-specific microRNAs promote induced pluripotency. Nat Biotechnol 27:459-61. doi: 10.1038/nbt.1535.

Kim K, Zhao R, Doi A, Ng K, Unternaehrer J, Cahan P, et al. 2011. Donor cell type can influence the epigenome and differentiation potential of human induced pluripotent stem cells. Nat Biotechnol 29:1117-9. doi: 10.1038/ nbt.2052.

Lakowski J, Han Y-T, Pearson RA, Gonzalez-Cordero A, West EL, Gualdoni S, et al. 2011. Effective transplantation of photoreceptor precursor cells selected via cell surface antigen expression. Stem Cells 29:1391-404. doi: 10.1002/ stem.694.

Lamb TM, Knecht AK, Smith WC, Stachel SE, Economides AN, Stahl N, et al. 1993. Neural induction by the secreted polypeptide noggin. Science 262:713-8. doi: 10.1126/science.8235591.

Lamba DA, McUsic A, Hirata RK, Wang P-R, Russell D, Reh TA. 2010. Generation, purification and transplantation of photoreceptors derived from human induced pluripotent stem cells. PLOS ONE 5:e8763. doi: 10.1371/ journal.pone.0008763.

La Torre A, Lamba DA, Jayabalu A, Reh TA. 2012. Production and transplantation of retinal cells from human and mouse embryonic stem cells. Methods Mol Biol 884:229-46. doi: 10.1007/978-1-61779-848-1_16.

Li H, Durbin R. 2009. Fast and accurate short read alignment with Burrows-Wheeler transform. Bioinformatics 25:1754-60. doi: 10.1093/bioinformatics/btp324.

Li Z, Rana TM. 2012. Using microRNAs to enhance the generation of induced pluripotent stem cells. Curr Protoc Stem Cell Biol 4:4A.4. doi: 10.1002/9780470151808.sc04a04s20.

Liao J, Wu Z, Wang Y, Cheng L, Cui C, Gao Y, et al. 2008. Enhanced efficiency of generating induced pluripotent stem (iPS) cells from human somatic cells by a combination of six transcription factors. Cell Res 18:600-3. doi: 10.1038/cr.2008.51.

Lin Y, Cheng Z, Yang Z, Zheng J, Lin T. 2012. DNp73 improves generation efficiency of human induced pluripotent stem cells. BMC Cell Biol 13:9. doi: 10.1186/1471-2121-13-9.

Lind KR, Ball KK, Cruz NF, Dienel GA. 2013. The unfolded protein response to endoplasmic reticulum stress in cultured astrocytes and rat brain during experimental diabetes. Neurochem Int 62:784-95. doi: 10.1016/j. neuint.2013.02.009.

Liu T, Zou G, Gao Y, Zhao X, Wang H, Huang Q, et al. 2012. High efficiency of reprogramming CD34+ cells derived from human amniotic fluid into induced pluripotent stem cells with Oct4. Stem Cells Dev 21:2322-32. doi: 10.1089/scd.2011.0715.

MacLaren RE, Pearson RA, MacNeil A, Douglas RH, Salt TE, Akimoto M, et al. 2006. Retinal repair by transplantation of photoreceptor precursors. Nature 444:203-7. doi: 10.1038/nature05161.

Mahmoudi S, Brunet A. 2012. Aging and reprogramming: a two-way street. Curr Opin Cell Biol 24:744-56. doi: 10.1016/j.ceb.2012.10.004.

Mali P, Chou B-K, Yen J, Ye Z, Zou J, Dowey S, et al. 2010. Butyrate greatly enhances derivation of human induced pluripotent stem cells by promoting epigenetic remodeling and the expression of pluripotency-associated genes. Stem Cells 28:713-20. doi: 10.1002/stem.402.

Marchetto MCN, Yeo GW, Kainohana O, Marsala M, Gage FH, Muotri AR. 2009. Transcriptional signature and memory retention of human-induced pluripotent stem cells. PLOS ONE 4:e7076. doi: 10.1371/journal. pone.0007076.

McGee TL, Seyedahmadi BJ, Sweeney MO, Dryja TP, Berson EL. 2010. Novel mutations in the long isoform of the USH2A gene in patients with Usher syndrome type II or non-syndromic retinitis pigmentosa. J Med Genet 47:499-506. doi: 10.1136/jmg.2009.075143.

Mekala SR, Vauhini V, Nagarajan U, Maddileti S, Gaddipati S, Mariappan I. 2013. Derivation, characterization and retinal differentiation of induced pluripotent stem cells. J Biosci 38:123-34. doi: 10.1007/s12038-012-9296-1.

Meyer JS, Howden SE, Wallace KA, Verhoeven AD, Wright LS, Capowski EE, et al. 2011. Optic vesicle-like structures derived from human pluripotent stem cells facilitate a customized approach to retinal disease treatment. Stem Cells 29:1206-18. doi: 10.1002/stem.674.

Meyer JS, Shearer RL, Capowski EE, Wright LS, Wallace KA, McMillan EL, et al. 2009. Modeling early retinal development with human embryonic and induced pluripotent stem cells. Proc Natl Acad Sci USA 106:16698-703. doi: 10.1073/pnas.0905245106.

Mukhopadhyay M, Shtrom S, Rodriguez-Esteban C, Chen L, Tsukui T, Gomer L, et al. 2001. Dickkopf1 is required for embryonic head induction and limb morphogenesis in the mouse. Dev Cell 1:423-34. doi: 10.1016/ S1534-5807(01)00041-7. 
Nakano T, Ando S, Takata N, Kawada M, Muguruma K, Sekiguchi K, et al. 2012. Self-formation of optic cups and storable stratified neural retina from human ESCs. Cell Stem Cell 10:771-85. doi: 10.1016/j. stem.2012.05.009.

Niibe K, Kawamura Y, Araki D, Morikawa S, Miura K, Suzuki S, et al. 2011. Purified mesenchymal stem cells are an efficient source for iPS cell induction. PLOS ONE 6:e17610. doi: 10.1371/journal.pone.0017610.

Obeng EA, Carlson LM, Gutman DM, Harrington WJ, Lee KP, Boise LH. 2006. Proteasome inhibitors induce a terminal unfolded protein response in multiple myeloma cells. Blood 107:4907-16. doi: 10.1182/ blood-2005-08-3531.

Okita K, Yamakawa T, Matsumura Y, Sato Y, Amano N, Watanabe A, et al. 2013. An efficient nonviral method to generate integration-free human-induced pluripotent stem cells from cord blood and peripheral blood cells. Stem Cells 31:458-66. doi: 10.1002/stem.1293.

Osakada F, Ikeda H, Mandai M, Wataya T, Watanabe K, Yoshimura N, et al. 2008. Toward the generation of rod and cone photoreceptors from mouse, monkey and human embryonic stem cells. Nat Biotechnol 26:215-24. doi: 10.1038/nbt1384.

Osakada F, Ikeda H, Sasai Y, Takahashi M. 2009. Stepwise differentiation of pluripotent stem cells into retinal cells. Nat Protoc 4:811-24. doi: 10.1038/nprot.2009.51.

Osakada F, Jin Z-B, Hirami Y, Ikeda H, Danjyo T, Watanabe K, et al. 2009. In vitro differentiation of retinal cells from human pluripotent stem cells by small-molecule induction. J Cell Sci 122:3169-79. doi: 10.1242/jcs.050393.

Pearson RA, Barber AC, Rizzi M, Hippert C, Xue T, West EL, et al. 2012. Restoration of vision after transplantation of photoreceptors. Nature 485:99-103. doi: 10.1038/nature10997.

Pera EM, Wessely O, Li SY, De Robertis EM. 2001. Neural and head induction by insulin-like growth factor signals. Dev Cell 1:655-65. doi: 10.1016/S1534-5807(01)00069-7.

Phillips MJ, Wallace KA, Dickerson SJ, Miller MJ, Verhoeven AD, Martin JM, et al. 2012. Blood-derived human iPS cells generate optic vesicle-like structures with the capacity to form retinal laminae and develop synapses. Invest Ophthalmol Vis Sci 53:2007-19. doi: 10.1167/iovs.11-9313.

Sasai Y, Eiraku M, Suga H. 2012. In vitro organogenesis in three dimensions: self-organising stem cells. Development 139:4111-21. doi: 10.1242/dev.079590.

Schwartz SD, Hubschman J-P, Heilwell G, Franco-Cardenas V, Pan CK, Ostrick RM, et al. 2012. Embryonic stem cell trials for macular degeneration: a preliminary report. Lancet 379:713-20. doi: 10.1016/ S0140-6736(12)60028-2.

Singh R, Shen W, Kuai D, Martin JM, Guo X, Smith MA, et al. 2013. iPS cell modeling of best disease: insights into the pathophysiology of an inherited macular degeneration. Hum Mol Genet 22:593-607. doi: 10.1093/ $\mathrm{hmg} / \mathrm{dds} 469$.

Stone EM. 2007. Leber congenital amaurosis - a model for efficient genetic testing of heterogeneous disorders: LXIV Edward Jackson Memorial Lecture. Am J Ophthalmol 144:791-811. doi: 10.1016/j.ajo.2007.08.022.

Szablowska-Gadomska I, Zayat V, Buzanska L. 2011. Influence of low oxygen tensions on expression of pluripotency genes in stem cells. Acta Neurobiol Exp (Wars) 71:86-93.

Takahashi K, Yamanaka S. 2006. Induction of pluripotent stem cells from mouse embryonic and adult fibroblast cultures by defined factors. Cell 126:663-76. doi: 10.1016/j.cell.2006.07.024.

Thomas CE, Ehrhardt A, Kay MA. 2003. Progress and problems with the use of viral vectors for gene therapy. Nat Rev Genet 4:346-58. doi: 10.1038/nrg1066.

Tucker BA, Anfinson KR, Mullins RF, Stone EM, Young MJ. 2013. Use of a synthetic xeno-free culture substrate for induced pluripotent stem cell induction and retinal differentiation. Stem Cells Trans/ Med 2:16-24. doi: 10.5966/ sctm.2012-0040.

Tucker BA, Park I-H, Qi SD, Klassen HJ, Jiang C, Yao J, et al. 2011. Transplantation of adult mouse iPS cell-derived photoreceptor precursors restores retinal structure and function in degenerative mice. PLOS ONE 6:e18992. doi: 10.1371/journal.pone.0018992.

Tucker BA, Redenti SM, Jiang C, Swift JS, Klassen HJ, Smith ME, et al. 2010. The use of progenitor cell/ biodegradable MMP2-PLGA polymer constructs to enhance cellular integration and retinal repopulation. Biomaterials 31:9-19. doi: 10.1016/j.biomaterials.2009.09.015.

Tucker BA, Scheetz TE, Mullins RF, DeLuca AP, Hoffmann JM, Johnston RM, et al. 2011. Exome sequencing and analysis of induced pluripotent stem cells identify the cilia-related gene male germ cell-associated kinase (MAK) as a cause of retinitis pigmentosa. Proc Natl Acad Sci USA 108:E569-76. doi: 10.1073/pnas.1108918108.

Vaché C, Besnard T, le Berre P, García-García G, Baux D, Larrieu L, et al. 2012. Usher syndrome type 2 caused by activation of an USH2A pseudoexon: implications for diagnosis and therapy. Hum Mutat 33:104-8. doi: 10.1002/ humu.21634.

Wang H, Yang H, Shivalila CS, Dawlaty MM, Cheng AW, Zhang F, et al. 2013. One-step generation of mice carrying mutations in multiple genes by CRISPR/Cas-mediated genome engineering. Cell 153:910-8. doi: 10.1016/j. cell.2013.04.025.

Zhang Z, Gao Y, Gordon A, Wang ZZ, Qian Z, Wu W-S. 2011. Efficient generation of fully reprogrammed human iPS cells via polycistronic retroviral vector and a new cocktail of chemical compounds. PLOS ONE 6:e26592. doi: 10.1371/journal.pone.0026592.

Zhang Z, Wu W-S. 2013. Sodium butyrate promotes generation of human iPS cells through induction of the miR302/367 cluster. Stem Cells Dev 22:2268-77. doi: 10.1089/scd.2012.0650. 